\title{
Future Financial Frameworks - Essentials for Risk-Based Capital Management
}

\author{
Nikolaus von Bomhard and Clemens Frey \\ Munich Reinsurance Company, Munich, Germany. \\ E-mail: cfrey@munichre.com
}

This article takes a global view of risk-based capital management in the insurance business, which nowadays is a key issue of the management of insurance companies. A thorough analysis of recent regulatory authorities' and rating agencies' positions shows that it is also a core topic in discussions about future financial frameworks in general. As a matter of fact, many parties are involved in the development of these frameworks, so there is an urgent need for common principles. This article identifies the essentials of future financial frameworks, highlights aspects which should be affected by a unified economic view, and outlines what progress has already been made.

The Geneva Papers (2006) 31, 46-56. doi:10.1057/palgrave.gpp.2510061

Keywords: risk management; capital management; primary insurance; reinsurance; Solvency II; solvency capital requirement; available capital

\section{Introduction}

Risk and capital management in insurance companies $^{1}$ is a complex field for management action. The complexity of risk-based capital management mainly stems from three sources:

- Risk-based capital management poses challenges for scientific and technological reasons: many different qualifications have to be brought together to cover all relevant themes, and many sources of information within one company have to be used before the full picture becomes clear. Managers are also challenged to understand the most important issues of risk within a company and to decide appropriately.

- Risk-based capital management necessarily has to be inclusive and coordinated, that is, it has to embrace all relevant types of risk and the overall risk exposure of a company. This means that many business functions have to be involved. Risk-based capital management is not an issue of an isolated group of people, nor can it be handled separately by subsidiaries of an insurance group.

- One has to assume that an insurer's risk management function will first of all base its assessment on an economic view of risk. An assessment of risks will, however, be strongly influenced by other views too. These are the views of regulatory

\footnotetext{
${ }^{1}$ In the following, the notions "insurance" and "insurer" will designate both primary insurance and reinsurance. If we intentionally differentiate between types of business, we will explicitly use the terms "primary insurance" and "reinsurance", respectively.
} 
or supervisory bodies and the views of rating agencies. The complexity even increases in the case of insurance groups operating in multiple regulatory environments.

So, in addition to the inherent challenges of risk-based capital management, the variety of parties involved makes it very difficult to handle the issue consistently. On the other hand, risk and capital management practices are currently undergoing rapid changes due to a number of reasons: variation in economic contexts like the strong bull run experienced by equity markets from 1996 to 2000, followed by severe falls of equity and corporate bond markets, effects of de-tariffication, but also increased scientific and practical knowledge about risk-based capital management as such.

Methodological developments have led to new qualities: measurement of necessary capital and capital management itself are becoming increasingly risk-adequate and comprehensive. Thus, a much more detailed view of risk and capital in insurance is possible today. Additionally, issues of risk-based capital management are nowadays broadly interpreted as top management responsibilities. ${ }^{2}$ This naturally includes the decision about a company's risk tolerance, the policy of asset-liability management, advanced accumulation control and value-based management techniques based on overall risk assessment and subsequent capital allocation.

There are positive moves which indicate that complexity and inconsistencies affecting current risk-based capital management could be repelled in the future. Regulatory bodies seem to be aiming at more consistent and economically motivated systems of legislation and supervision (e.g. Solvency II), and rating agencies are changing their attitudes concerning the use of insurance-specific means of risk measurement and management.

This situation offers the chance of coordinating the different views on risk-based capital, not only at a European level, but also worldwide. ${ }^{3}$ It is a perfect opportunity to create a real level playing field for primary insurance and reinsurance companies in Europe, and we would like to foster this exercise by highlighting issues that seem most important to us. In particular, we would like to reflect on the discussion in Europe, while bearing worldwide aspects in mind.

\section{General framework principles}

We think that the development of future standards on risk-based capital management should be based on a small set of principles. These principles are essential to future solvency requirements but should also be obeyed by rating agencies and by the insurance industry itself when measuring and managing risk-based capital: ${ }^{4}$

\footnotetext{
${ }^{2}$ In North American insurance, 70 per cent of the companies have delegated responsibilities for risk management to a CRO, CFO or a Risk Management Committee, and in about 90 per cent of the cases risk management functions report to CEO, CFO or the Board of Directors (see Tillinghast (2004)).

${ }^{3}$ Explicit indications of the worldwide process are the activities of IAIS and IAA, manifest in the papers Towards a common structure and common standards for the assessment of insurer solvency: Cornerstones for the formulation of regulatory financial requirements (IAIS (2005)) and A Global Framework for Insurer Solvency Assessment (IAA (2004)).

${ }^{4}$ Statements about risk-based capital and management strongly depend on the definitions used. Any assessment of the solvency of a company consists of comparing solvency capital requirements (or simply
} 


\section{- Maximum harmonisation}

Financial frameworks should not pose artificial distortions to markets. Thus, solvency regulations in different countries should be harmonised, but they should also be compatible with rules set for rating capital demands and best practices with respect to economic capital as applied by the insurance industry.

- Transparency

Transparent supervisory and rating action makes decisions understandable and fosters the spread of information, best practice and market discipline.

- Risk-adequate solvency assessment

Solvency assessment should be risk-adequate and based on the individual exposure of an insurance company. Obeying this principle will serve the stability of and consequently confidence in financial markets. ${ }^{5}$ Since the risk assessments are individually tailored, this allows warning signs to be noted early enough so that countermeasures can be taken, though it does not pose an overly heavy burden on those companies which perform well.

- Economic viewpoint

An economic point of view should be adhered to, if possible, in every solvency and rating decision. In particular, it implies the use of a total balance sheet approach, that is, taking the most general view on the solvency of a company. We think viewing solvency economically is absolutely key to future financial frameworks. Risk-based (economic) capital and solvency capital cannot basically be the same, for they serve different purposes and are defined by different stakeholders. The first one has to be defined by the management of an insurance company based on its risk preferences; the second one is defined by supervisory authorities, with the intention of providing a certain protection for policyholders. In addition, there are contingent accounting considerations (IFRS), of course, and rating agencies which assess among other issues - the current security of a company. In spite of their different purposes, however, we think that by building them onto a common, economic basis they will be more consistent, more operational and more comparable than ever before. This will in turn best serve the purpose of protecting policyholders' and shareholders' interests.

As we have stated above, assessment of a company's solvency does not only entail a calculation or modelling exercise aimed at assessing all the risks a company bears (and thus the required capital). It is also a matter of rules for available capital and

required capital, which is calculated by capital models based on the risks an insurance company faces) and available capital (which is calculated according to specific rules from available assets). Depending on the definitions and rules used, we differentiate between economic (a company's), regulatory (a supervisory authority's) and rating (a rating agency's) views on capital. It is important to note that a company's solvency does not exclusively depend on the ratio of available and required capital, but also on additional qualitative factors regarding risk-based capital management.

${ }^{5}$ IAIS states: "Supervisory authorities are concerned with maintaining efficient, fair, safe and stable insurance markets for the benefit and protection of policyholders. When provided with appropriate information, markets can act efficiently, rewarding those insurers that operate effectively and penalising those that do not. This aspect of market discipline serves as an adjunct to supervision" (IAIS (2003)). See also the remarks referring to the background of prudential supervision in EU Commission (May 2002). 
processes of managing risk and capital, that is, of the quality of risk-based capital management as such. One could also call this a general risk management culture of a company. We address both aspects in the following sections, which focus on the measurement of required and available capital and on essentials of diversification.

\section{Essentials of capital measurement}

So what do the above-mentioned principles mean for the measurement of required and available capital in the contexts of rating and regulation?

\section{Internal capital models}

From an economic, risk-oriented viewpoint, there is a natural desire to steer insurance business based on internally available information and its interpretation by experts: a company's loss experience and current exposure are key data for doing this. Today's stochastic capital models are built upon this information. They are tools to yield business information necessary for risk-based capital management, including risk measurement, accumulation control, risk capital allocation, performance management, etc. In our opinion, internal models should be built bottom-up, comprising all relevant and reliably quantifiable risk classes ${ }^{6}$ together with their dependencies.

Primary insurers and reinsurers should be permitted and encouraged to determine their capital requirements for regulatory and rating agency purposes based on an internal model approach. Recent regulatory systems already address the issue of internal models. The use of internal models for solvency purposes is allowed by the British Financial Services Authority (FSA) and the Australian Prudential Regulation Authority (APRA), for example. The development of the Swiss Solvency Test shows that internal models will even be mandatory for insurance businesses which are too special to allow for a standardized solvency assessment, for example, reinsurance. ${ }^{7}$ Within the framework of Solvency II, internal models are seemingly also going to play a prominent role. They are obviously seen as part of proper risk management as compared to the limited potential of standardized approaches, so the EU Commission seeks to encourage their use. ${ }^{8}$

\section{Risk margins on technical provisions}

Solvency capital requirements are only one part of future solvency systems. Such requirements typically refer to a relatively short time horizon (e.g., 1 year) and are

\footnotetext{
${ }^{6}$ These should be at least market, credit, underwriting, and to the extent measurable also operational risks.

7 "The reason that no standard model will be supplied for reinsurers lies in the fact that given the divergent nature of business written by different reinsurers, a standard model would be unduly complicated if it were to capture the risk correctly" (FOPI (2004, p. 25)).

8 " $[\ldots]$ in order to encourage companies to continuously focus on risk management (both at entity and group levels) it is desirable that internal models be developed and used in the EU." (EU Commission (2004)).
} 
intended to keep an insurance company a going concern. In addition to these capital requirements, it is expected that there will be a so-called risk margin on provisions. Economic rationale also dictates that reserves have to be discounted. The margin covers the whole run-off period of the particular reserves and is intended to protect the policyholders' interests by allowing - in stress situations - the transfer of reserves to another insurance company. It may also be defined as a certain percentile of the ultimate distribution of reserves in order to fulfill liabilities with a certain degree of confidence. We think it is core to the understanding of the risk margin that it should be conditional on the portfolio. Methods for quantifying the margin still have to be agreed on in a principles-based way to avoid double counting of risks (i.e. in capital requirements and in risk margin).

\section{Qualitative requirements of risk measurement}

The widespread use of internal models and methods for setting reserves (including a risk margin) precludes the existence of common standards. The latter should be based on principles and thus enable the development and refinement of model approaches. Regulators and rating agencies are currently striving to establish such a widely accepted set of transparent rules. Standard and Poor's, for example, intends to consider enterprise risk management models used by insurers. ${ }^{9}$ Supervisory authorities organized within CEIOPS ${ }^{10}$ also discuss the main lines of acceptance of internal models. ${ }^{11}$

We think there are some core topics on which the acceptance of internal models depend. These are an internal model strongly embedded in the company's business processes, responsibility taken by senior management, and detailed documentation of internal model assumptions, methods and calculations to be disclosed to the supervisory authority. Assuming these conditions are fulfilled, supervisors should not impose arbitrary capital add-ons on the internal model results. This would lead to overly prudent capital requirements which in turn force an insurance company to hold deadweight capital, that is, capital beyond an economically reasonable amount.

\section{Harmonized definitions of economic capital}

Currently, there are many definitions of available capital, both in rating and regulatory contexts. We think that the increasing use of internal models offers an excellent opportunity for rating agencies and regulators to harmonize their definitions of economic capital and to abandon arbitrary haircut factors in determining available financial resources. The reason for this is that market, credit, concentration and matching risks can be included mainly in internal models, but also in standardized methods of calculating solvency capital requirements. So qualitative rules on available capital can be skipped to a large extent, leaving only a negative list of non-allowable

\footnotetext{
${ }^{9}$ See Standard \& Poor's (2005).

${ }^{10}$ CEIOPS - Committee of European Insurance and Occupational Pensions Supervisors.

${ }^{11}$ See CEIOPS (2004, p. 110f).
} 
financial instruments. This would address the urgent need to reduce the complexity of solvency frameworks and leave space for the development of innovative forms of financial instruments.

\section{Standard formulas - role and restriction}

There are some readily implemented instances of standard formulas, some already in place for years. There is, for example, the American model developed by the National Association of Insurance Commissioners. The British formula, which is used for calculating Enhanced Capital Requirements, and the Australian formula, which was set in force in $2002,{ }^{12}$ are parts of more recent regulations. In Germany, the German Insurance Association (GDV) is about to develop ${ }^{13}$ a new standard formula, which is broadly compatible with the building blocks for standardized approaches set out by the Comité Européen des Assurances (CEA). ${ }^{14}$ Since this formula has some favourable characteristics, ${ }^{15}$ it is - once finished - intended to be fed into the European decisionmaking processes, just like the formulas already in place. The Swiss Federal Office of Private Insurance (FOPI) is about to establish a new solvency system too. This system follows a more complex approach; nevertheless, it is designed to be compatible with Solvency II. ${ }^{16}$

But what is the role of standard formulas in solvency systems in general - and what are the restrictions of this role? IAIS ${ }^{17}$ has described the basic setup of solvency regimes: ${ }^{18}$ "the solvency regime allows a set of standardized and more advanced approaches to determine the solvency requirements, and includes the use of internal models if appropriate".

IAIS acknowledges that for certain lines of business or particular insurance undertakings standardized approaches may well suffice. Standardized approaches (standard formulas) form the basis of a robust and generally applicable quantitative solvency regime for primary insurance. However, internal capital models are the model of choice when it comes to an exact and reliable measurement of risk or the risks to be measured are quite special.

12 British and Australian approaches to regulation seem to have a strong impact on the discussions about Solvency II. This can be observed equally in documents issued by the EU Commission and by CEIOPS (e.g. in the EU Commission's draft framework paper MARKT/2506/04 and in the supervisors' draft answers to the second wave of calls for advice CEIOPS-CP-04/05).

13 The new GDV Standard Formula is developed with active involvement of actuaries and the German Federal Financial Supervisory Authority (BaFin).

${ }^{14}$ CEA (2005, p. 9f).

15 The draft GDV Standard Formula may well fill the gap between simple factor formulas and fully fledged stochastic capital models. It explicitly allows for correlation and diversification, accounts for companyspecific loss experience and implements a special treatment of accumulation loss events.

16 " $[\ldots]$ it is an aim of the SST [Swiss Solvency Test] to be compatible with the future European Solvency II framework" (Swiss Federal Office of Private Insurance (FOPI (2004, p. 7f)).

${ }^{17}$ IAIS - International Association of Insurance Supervisors.

${ }^{18}$ See IAIS (2005, p. 10). 
As opposed to primary insurance undertakings, there is hardly any way to apply a standardized approach to calculate a reinsurer's solvency capital requirement. This is due to the fact that reinsurance business is very special and requires a very accurate and tailored risk analysis. This is the reason why FOPI, for example, will not supply a standard formula for reinsurance business; they explicitly demand an internal model instead. Thus, internal models are the only and the most appropriate method for reinsurance undertakings to measure required risk capital.

A very similar consideration is valid for insurance groups. In this case, there are structural reasons that do not allow the application of standardized approaches at group level, since they cannot adequately capture the special structures and mutual dependencies between entities within a group.

\section{Reinsurance and credit risk}

The most important tool of risk mitigation in primary insurance is reinsurance. ${ }^{19}$

- This means that regulators and accounting bodies should review their policies toward risk mitigation. Currently, insurers and reinsurers are actively discouraged or forbidden from adopting sensible risk mitigation strategies because of arbitrary accounting treatment or because of restrictions on allowable hedging instruments in some jurisdictions.

- Primary insurers should not be penalized for placing all their reinsurance requirements with one reinsurer. There are no limits to the level of risk mitigation permitted by insurers hedging their financial risks with one bank counterparty likewise, there ought to be no limit or penalty for a primary ceding all its reinsurance requirements to one reinsurer. Insurers are already required to capitalize for all counterparty credit risks (including reinsurer credit risks), so they should not be further penalized.

There are other means of risk mitigation, for example, hedging of investment risks or methods of alternative risk transfer that are also covered by the term risk mitigation. All of those measures should be adequately allowed for in internal models.

\section{Essentials of diversification}

Using effects of diversification is the basic principle of primary and reinsurance business. This implies that risk diversification - together with concentration and dependencies between risks - has to be taken into account in all quantitative assessments of risks in the insurance industry. As management action should use the results of risk measurement, it will subsequently ensure the optimal use of diversification within and across entities within a group.

\footnotetext{
19 The EU Commission (2004, Annex 2, p. 29) acknowledges this on a general level by saying: "Reinsurance is the key risk management tool in insurance, notably in non-life insurance, but also in life assurance, and is used in particular to mitigate certain volatile or extreme insurance risks" (2004, Annex 2, p. 29), but this is also true in an individual sense: "An insurer's reinsurance program forms a major part of its core risk management processes" (EU Commission (2002, p. 13)).
} 


\section{Levels of diversification}

Diversification is present to a varying extent in different insurance companies. Its effects depend on the particular liability and asset portfolio, business activities and involvement of a company in different countries. There are four distinct conceptual levels of diversification. A subgroup of the Chief Risk Officer Forum (CRO Forum) has analysed diversification in the insurance industry and identified the following levels of diversification: ${ }^{20}$

- Level 1: Within-risk types

This level of diversification is observable in a homogenous insurance portfolio. A risk type may be a risk class (i.e. market risk, underwriting risk, etc.) or a line of business.

- Level 2: Across-risk types

This relates to diversification between risk types, for example, between a motor portfolio and a household portfolio, or between underwriting and market risks.

- Level 3: Across entities within a geographical region

This level is relevant for insurance groups where separate legal entities operate in the same geographical or legislative environment.

- Level 4: Across geographical regions or regulatory legislations

This level is relevant for insurance groups operating on a worldwide basis, for instance.

\section{Dependencies between risks}

Diversification is bounded by dependencies between different risk types, or, more generally speaking, by concentration. Dependencies between the different risks are not constant: in stress situations they might increase (e.g. only a major natural catastrophe affecting the insurance industry may have an impact on stock markets). Nevertheless, diversification exists even under stressed conditions. ${ }^{21}$ Diversification effects also vary between companies since they depend on the particular portfolio. From a production viewpoint, the better diversified an insurer is, the more effective it can offer riskbearing capacity. Because of this, reinsurance is a necessary factor in insurance markets because it allows primary insurers to take advantage of the worldwide diversification $^{22}$ of a global reinsurance company.

So we think that diversification effects must be recognized:

- when risk factors, their dependencies and the company's exposure to them are identifiable;

- when they are supported by empirical, technical, scientific or expert opinion of causal linkages;

- when considered in business decision-making;

\footnotetext{
${ }^{20}$ CRO Forum (2005, p. 20f).

${ }^{21}$ Ibid., p. 14.

${ }^{22}$ This is level 4 diversification in the CRO Forum Paper.
} 
- where capital/risk mobility does not impose barriers to diversification being realizable.

Most importantly, this is not only valid for the calculation of required capital, but also for the calculation of risk margins on top of technical provisions. It implies that risk margins should always be considered in relation to the whole underlying portfolio of an entity.

\section{Allowance for diversification in standard formulas}

In current standardized models for solvency assessment, diversification is allowed for either implicitly (as in the U.K. or Australia) or explicitly (as in the draft GDV model). In any case, such models are viable for a certain average insurance company. Diversification effects, although present, have to be measured quite prudently in standardized approaches. Thus, there is an additional incentive for internal models, that is, to measure diversification and concentration more accurately than any standardized model will ever do.

\section{Capital mobility vs. risk mitigation in groups}

The above-mentioned levels 3 and 4 of diversification are valid only for groups of insurance companies, since they spread risks across entities and possibly also across geographical regions and legislations. In this case, that is, if beneficial across multiple entities within the same group, the extent to which capital can move between the different entities has to be taken into account. An awareness of how truly mobile capital is within a group is critical to understanding group solvency. It has to be borne in mind, however, that internal risk mitigation is a very effective tool of risk-based capital management within a group. Risk mitigation between entities of a group is just complementary to capital mobility. This means that diversification effects, capital mobility and risk transfer should be recognized under the condition that financial resources are available to back policyholders' and other creditors' claims with sufficient economic value and as they fall due.

The important point about capital mobility is that risk mitigation and capital mobility are not severely disturbed by potential non-aligned action of national supervisory bodies. It is crucial that the various national supervisory authorities which an insurance group has to deal with cooperate to the best extent possible. The co-coconcept $^{23}$ is a first valuable step in this direction, and the idea of increasing the transparency of supervisory action and peer reviews ${ }^{24}$ between supervisors seems valuable to the extent that they encourage the consistency of several supervisory authorities' actions. Generally, however, the concept of a lead supervisor ${ }^{25}$ should be implemented.

\footnotetext{
${ }^{23}$ For details on supplementary supervision, see CEIOPS (2005).

${ }^{24}$ See EU Commission (2004, Annex 2, p. 48).

${ }^{25}$ For an extensive discussion of this idea, see European Financial Services Round Table (2004).
} 


\section{Legally binding obligations}

There is another restricting aspect of diversification within groups. Regulatory authorities sometimes cite the contagion problem, that is, the risk that a subsidiary is hit by certain problems caused by other group entities. Regulators have argued that increased contagion risk offsets the benefits of group (multi-jurisdictional) diversification. It is important that regulators at this point develop a more balanced view of diversification and obey the above-mentioned principle.

Legally binding obligations are a means of addressing the myth that large global players in insurance have a history of "walking away" from troubled subsidiaries. This would imply that they should not be allowed to take credit for diversification benefits at levels 3 and 4 . As soon as there are written commitments to honour their global obligations, this will make risk assessment more transparent and enable an explicit allowance for diversification effects also on a global level.

\section{Conclusions}

Every insurance market in Europe and in the world has its specific issues and its specific history, so each of them can contribute something towards the worldwide process of standardizing solvency requirements. This is also true for the different stakeholders in this process, that is, regulatory and supervisory authorities, rating agencies and the insurance industry itself.

Principles like transparency, risk adequacy and the economic view of business can help lay the groundwork of the future financial system. We have visualized some essentials of capital management and diversification in order to accelerate the goal of harmonization between the various frameworks currently in existence, which make risk-based capital management still a thoroughly complex exercise nowadays.

\section{References}

CEA (2005) Solvency II - Building Blocks for the Solvency II Project, ECO 5126(05/05), Brussels. CEIOPS (2005) Answers to the second wave of calls for advice, CEIOPS-DOC-07/05, October 2005.

CEIOPS (2005) Guidelines for Coordination Committees, CEIOPS-DOC-02/05, February 2005.

CEIOPS (2004) Consultation Paper No. 7, CP-04/05.

CRO Forum (2005) A framework for incorporating diversification in the solvency assessment of insurers, The Chief Risk Officer Forum, June 2005.

EU Commission (2004) MARKT/2506/04, December 2004.

EU Commission (2002) Study into the methodologies to assess the overall financial position of an insurance undertaking from the perspective of prudential supervision, study conducted by KPMG, May 2002.

European Financial Services Round Table (2004) Towards a Lead Supervisor for Cross Border Financial Institutions in the European Union, European Financial Services Round Table, June 2004.

FOPI (2004) White Paper of the Swiss Solvency Test, Swiss Federal Office of Private Insurance (FOPI), November 2004.

IAA (2004) A Global Framework for Insurer Solvency Assessment.

IAIS (2005) Towards a common structure and common standards for the assessment of insurer solvency Cornerstones for the formulation of regulatory financial requirements, October 2005. 
IAIS (2003) Insurance core principles and methodology, ICP26, October 2003.

Standard \& Poor's (2005) Insurance Critreria: Evaluating the Enterprise Risk Management Practices of Insurance Companies, October 2005.

Tillinghast (2004) Adding Value Through Risk and Capital Management - 2004 ERM Survey Update.

\section{About the Authors}

Nikolaus von Bomhard is Chairman of the Board of Management of Munich Re. Clemens Frey works as a consultant in the Integrated Risk Management Unit of Munich Re. 